\title{
Contribuição ao estudo da atividade antifúngica de Maytenus ilicifolia Mart. ex Reiss., Celastraceae
}

\author{
Cunico, M. M. ${ }^{1}$; Cirio, G. M.2; Miguel, O. G. ${ }^{1 *}$; Miguel, M. D. ${ }^{1}$; \\ Montrucchio, D. P. ${ }^{1}$; Auer, C. G. ${ }^{3}$; Grigoletti Júnior, A. ${ }^{3}$ \\ ${ }^{1}$ Laboratório de Fitoquímica, Departamento de Farmácia; \\ ${ }^{2}$ Departamento de Fitotecnia e Fitossanitarismo; Universidade Federal do Paraná, Curitiba, PR; \\ ${ }^{3}$ EMBRAPA Florestas, Colombo, PR.
}

\begin{abstract}
RESUMO: Maytenus ilicifolia Mart. ex Reiss, Celastraceae, espinheira-santa, é nativa em muitas partes da América do Sul, sendo encontrada no sul do Brasil. É utilizada no tratamento de gastrite, úlceras e outras desordens do estômago, na forma de decocção das folhas ou extrato liofilizado em cápsulas. Neste trabalho, estudou-se a atividade antifúngica do seu extrato etanólico sobre 0 crescimento micelial dos fungos fitopatogênicos Colletotrichum acutatum, Fusarium oxysporum e Cylindrocladium spathulatum. Na comparação do crescimento micelial de isolados desses fungos em BDA (Batata Dextrose Agar), adicionados do extrato etanólico da espinheira-santa, foi observado que o mesmo inibiu em mais de $10 \%$ o crescimento micelial de Fusarium oxysporum, nas três concentrações avaliadas $(0,2 ; 0,4$ e $0,6 \mathrm{mg} / \mathrm{mL})$, estimulou o crescimento micelial de Colletotrichum acutatum em mais de $30 \%$ na concentração de $0,2 \mathrm{mg} / \mathrm{mL}$, e algumas de suas frações inibiram o desenvolvimento de Cylindrocladium spathulatum.
\end{abstract}

Unitermos: Maytenus ilicifolia; Fusarium oxysporum; Colletotrichum acutatum; Cylindrocladium spathulatum; espinheira-santa; atividade antifúngica.

ABSTRACT: Study of antifungal activity of Maytenus ilicifolia Mart. ex Reiss., Celastraceae. Maytenus ilicifolia Mart. ex Reiss., Celastraceae, known as espinheira-santa, is native to South America, and in southern Brazil its leaves decoction is traditionally used for the treatment of gastritis, ulcers and other gastrointestinal disorders. The objective of this work was to investigate the effect of the crude ethanolic extract of espinheira-santa on the mycelial growth of three phytopathogenical fungi: Colletotrichum acutatum, Fusarium oxysporum and Cylindrocladium spathulatum. It was observed that this extract inhibited in more than $10 \%$ the mycelial growth of Fusarium oxysporum at all used concentrations $(0.2 ; 0.4$ and $0.6 \mathrm{mg} / \mathrm{mL})$, stimulated the Colletotrichum acutatum mycelial growth in more than $30 \%$ at $0.2 \mathrm{mg} / \mathrm{mL}$ and some of its fractions inhibited the Cylindrocladium spathulatum development.

Key words: Maytenus ilicifolia; Fusarium oxysporum; Colletotrichum acutatum; Cylindrocladium spathulatum; espinheira-santa; antifungal activity. 


\section{INTRODUÇÃO}

O efeito agressor ao meio ambiente acarretou inúmeros desequilíbrios ecológicos em diversas regiões agrícolas. Atualmente, a grande preocupação com o meio ambiente tem levado inúmeros pesquisadores a buscarem alternativas viáveis, efetivas e seguras no controle de pragas e doenças que acometem culturas de plantas de interesse comercial (KIMATI et al., 1997a).

As plantas medicinais representam uma importante fonte de substâncias fungitóxicas, as quais, quando comparadas com fungicidas de origem sintética, caracterizam uma proposta ecológica praticamente inofensiva ao meio ambiente (STANGARLIN et al., 1999).

A Maytenus ilicifolia Mart. ex Reiss, Celastraceae, é uma arvoreta ou árvore de 4 a $5 \mathrm{~m}$ de altura, originária da América do Sul e do sul do Brasil, empregada popularmente em decoctos das partes aéreas frescas ou secas e estabilizadas e pela indústria farmacêutica como extrato liofilizado em cápsulas (ALONSO, 1987; CARLINI,1988). Ela possui em sua composição química alcalóides, polifenóis, diterpenos, triterpenos do tipo friedelano, sesquiterpenos, entre outros (STELLFELD, 1934; CORREA JUNIOR et al., 1994), podendo apresentar alguma atividade antifúngica (LIMA, 1971).

O fungo Colletotrichum acutatum é causador da doença conhecida como antracnose, sendo susceptíveis ao ataque os tecidos novos de ramos, folhas, flores e frutos de citrus e nos rizomas, flores e frutos de morangueiro, produzindo lesões. O fungo Fusarium oxysporum está presente no solo e é causador de "damping off" em sementeiras e murchas vasculares em viveiros de mudas e culturas de importância econômica. O fungo Cylindrocladium spathulatum é causador da pinta-preta em folhas adultas, sendo a principal doença fúngica da erva-mate, causando em viveiro e no campo até $30 \%$ de perdas de mudas (KIMATI et al., 1997b).

Assim sendo, objetivou-se realizar a investigação da atividade antifúngica do extrato etanólico da Maytenus ilicifolia.

\section{MATERIAIS E MÉTODOS}

\section{Isolados de fungos}

Os isolados patogênicos de Fusarium oxysporum, Colletotrichum acutatum e Cylindrocladium spathulatum foram fornecidos pelo Centro de Diagnóstico Marcos Enrietti, da Secretaria de Agricultura do Estado do Paraná e pela EMBRAPA Florestas.

\section{Material vegetal}

Folhas de Maytenus ilicifolia foram adquiridas, em abril de 2001, no comércio local de Curitiba, no Mercado Municipal, na Rua General Carneiro nos boxes: Arauana e Assel Ervas Medicinais e Produtos Naturais, provenientes de Colombo, no Estado do Paraná. A identificação da espécie foi realizada pelo Dr. Gerdt Hatschbach do Museu Botânco Municipal (MBM) da Prefeitura de Curitiba-Paraná e um exemplar desta espécie (exsicata) encontra-se depositado no herbário deste museu (MBM), sob número 248503. 


\section{Preparação do extrato bruto}

Folhas de Maytenus ilicifolia (1100 g), secas e estabilizadas, foram submetidas a extração em percolador de Robiquet, método $(A)$ da Farmacopéia Brasileira (I ed.), o qual foi submetido à concentração em rotavapor até redução a $1 / 5$ de seu volume, com obtenção do extrato bruto etanólico total (EBEtOH), de aspecto xaroposo e escuro, apresentando $30,45 \mathrm{~g}$ de resíduo seco. Em seguida, alíquotas deste extrato foram levados à completa secura, afim de serem utilizadas nos ensaios biológicos.

\section{Ensaios biológicos}

Para a avaliação da atividade fungitóxica do extrato etanólico bruto (EBEtOH) utilizou-se o método adaptado de AUER \& BETTIOL (1986) e STANGARLIN et al. (1999). Para tal, isolados do Fusarium oxysporum (café) e Colletotrichum acutatum (morango) foram incorporados separadamente em meio de cultivo BDA (Batata-Dextrose-Ágar), cada um nas concentrações de 101,203 e $304 \mathrm{mg} / \mathrm{mL}$, autoclavados a $120^{\circ} \mathrm{C}$ e 1 atm por $15 \mathrm{~min}$. O pH das soluções encontravamse em torno de 5,5, antes da esterilização. Após uma hora do meio BDA contendo os extratos etanólicos ter sido vertido nas placas de Petri, foram inoculados esporos dos patógenos $F$. oxysporum e $C$. acutatum, com 7 dias de idade, e em seguida, incubados a $25^{\circ} \mathrm{C}$ no escuro, após vedação com filme plástico. As testemunhas (controles) continham apenas o meio BDA. $O$ delineamento experimental foi inteiramente casualizado com seis repetições. As avaliações foram realizadas por meio de medições do diâmetro das colônias (média de duas medidas perpendiculares), após cinco dias de incubação dos patógenos.

Como o delineamento experimental foi inteiramente casualizado, a análise estatística dos resultados obtidos foi realizada por meio do Teste de Tukey (limite de confiança de $95 \%$ ), utilizandose o programa SANEST (ZONTA et al., 1984).

Também foram utilizadas para a realização do bioensaio por cromatografia em camada delgada (CDD) alíquotas de $50 \mu \mathrm{L}$ do $\mathrm{EBEtOH}$, empregando-se o método adaptado de Stangarlin et al. (1999). Placas de gel de sílica $G_{254}$, pré-lavadas com clorofórmio: metanol (1:1 - v/v), foram preparadas e após a aplicação das amostras sobre as placas e secagem sob fluxo de ar, realizouse a separação dos compostos utilizando-se o sistema diclorometano: metanol: água (95:05:0,5 - v/v/v). Os compostos foram vizualizados sob luz visível e ultravioleta (UV) a 365 e $254 \mathrm{~nm}$ e, em seguida, as placas secas contendo as bandas individuais foram aspergidas com suspensão de esporos de $F$. oxysporum $\left(1,4 \times 10^{6}\right.$ esporos/ 0,4 $\mathrm{mL}$ de meio líquido Batata-dextrose - BD, 10 pulverizações), C. acutatum $\left(1,0 \times 10^{6}\right.$ esporos/ $0,2 \mathrm{~mL}$ de meio líquido $\mathrm{BD}, 5$ pulverizações) e Cylindrocladium spathulatum, isolado de erva-mate $\left(1,0 \times 10^{5}\right.$ esporos/ 1,6 mL de meio líquido $\mathrm{BD}, 40$ pulverizações), e mantidas sob umidade relativa de $100 \%$ a $25{ }^{\circ} \mathrm{C}$ e luz. Após 7 dias, verificou-se a ocorrência de zonas de inibição de crescimento micelial ao redor das bandas individuais, quando presentes.

\section{RESULTADOS E DISCUSSÃO}

Comparando-se o crescimento micelial dos isolados dos patógenos testados nos meios de cultura contendo EBEtOH com o tratamento controle, verificou-se uma atividade antifúngica sobre o patógeno $F$. oxysporum diretamente proporcional à quantidade de extrato no meio de cultura, e uma atividade genestática sobre $C$. acutatum (Tabela1).

Também verificou-se que os melhores resultados obtidos nesta avaliação foram aqueles com o EBEtOH na concentração de $0,6 \mathrm{mg} / \mathrm{mL}$, cuja inibição do crescimento do patógeno $F$. oxysporum superou o valor de $25 \%$ (Tabela 1 ). 
Tabela 1. Efeito do extrato bruto etanólico (EBEtOH) de Maytenus ilicifolia, em várias concentrações, sobre o crescimento micelial de patógenos.

\begin{tabular}{|c|c|c|c|c|c|c|c|}
\hline \multirow{3}{*}{ AMOSTRA } & \multirow{3}{*}{$\begin{array}{l}\text { Concentração } \\
\text { do EBEtOH } \\
\text { em meio BDA }\end{array}$} & \multicolumn{3}{|c|}{ Fusarium oxysporum } & \multicolumn{3}{|c|}{ Colletotrichum acutatum } \\
\hline & & \multicolumn{2}{|c|}{$\begin{array}{l}\text { Média dos halos } \\
\text { de crescimento } \\
\text { micelial } \\
\text { (mm) }\end{array}$} & \multirow{2}{*}{$\begin{array}{c}\text { Inibição do } \\
\text { crescimento } \\
\text { micelial } \\
(\%)\end{array}$} & \multicolumn{2}{|c|}{$\begin{array}{l}\text { Média dos halos } \\
\text { de crescimento } \\
\text { micelial } \\
\text { (mm) }\end{array}$} & \multirow{2}{*}{$\begin{array}{c}\text { Inibição do } \\
\text { crescimento } \\
\text { micelial } \\
(\%)\end{array}$} \\
\hline & & EBS & Controle & & EBS & Controle & \\
\hline EBEtOH & $0,2 \mathrm{mg} / \mathrm{mL}$ & $5,0 \mathrm{a}$ & & 10 & $5,2 \mathrm{a}$ & & -30 \\
\hline (folhas) & $0,4 \mathrm{mg} / \mathrm{mL}$ & $4,3 a$ & $5,5 b$ & 22 & $4,5 \mathrm{a}$ & $4,0 \mathrm{~b}$ & -12 \\
\hline & $0,6 \mathrm{mg} / \mathrm{mL}$ & $4,1 \mathrm{a}$ & & 26 & $4,0 \mathrm{~b}$ & & 0 \\
\hline
\end{tabular}

Médias seguidas de mesma letra não diferem estatisticamente entre si (Tukey - $5 \%$ ) - média de 6 repetições casualizadas. A inibição do crescimento micelial de patógenos frente ao extrato, em várias concentrações, foi obtida pela comparação das médias das colônias fúngicas do tratamento com as das testemunhas (Controles). Os valores negativos referem-se aos efeitos genestáticos.

Estudo similar foi realizado com extratos aquosos brutos das plantas medicinais Ocimum basilicum (alfavaca), Ruta graveolens (arruda) e Baccharis trimera (carqueja), as quais apresentaram atividade antifúngica sobre Rhizoctonia solani, Sclerotium rolfsii, Alternaria alternata, Phytophthora sp. e Colletotrichum graminicola (STANGARLIN et al., 1999).

Também observou-se pelo bioensaio por CCD, realizado para a detecção de compostos fungitóxicos presentes no EBEtOH das folhas de Maytenus ilicifolia, a presença de duas frações bem definidas, que causaram inibição do desenvolvimento de Cylindrocladium spathulatum, conforme Figura 1.

Testemunha

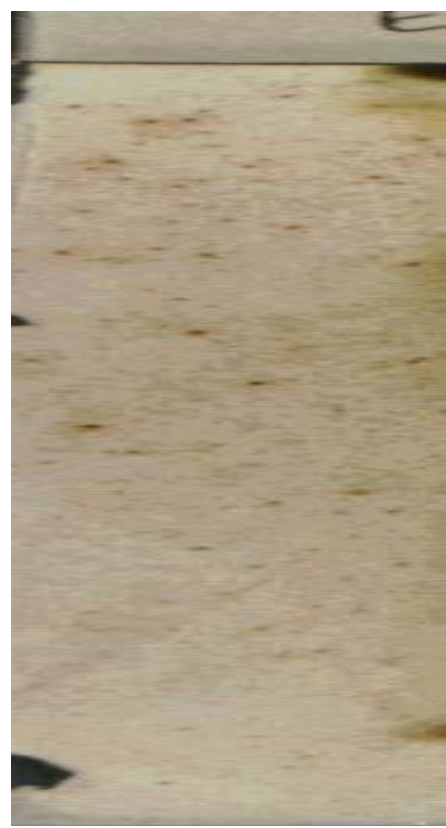

Extrato etanólico bruto

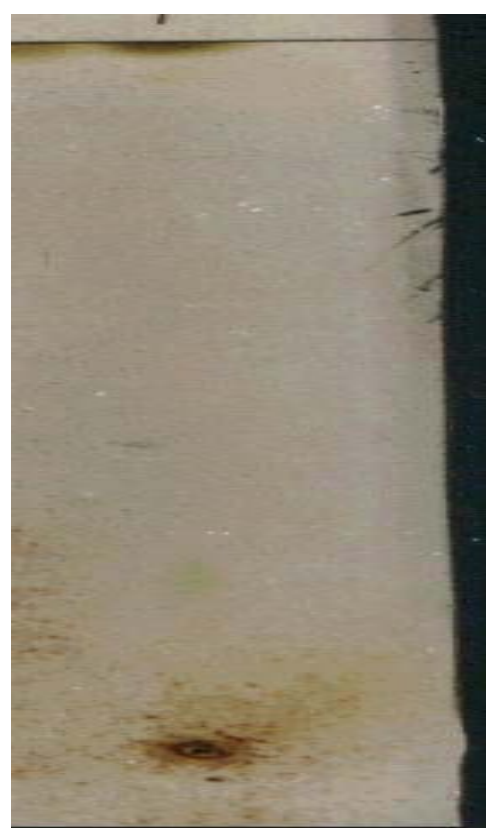

Figura 1. Zonas de inibição do crescimento de Cylindrocladium spathulatum frente a frações do extrato etanólico bruto de Maytenus ilicifolia no bioensaio por cromatografia em camada delgada. 


\section{CONCLUSÃO}

O extrato etanólico bruto das folhas de Maytenus ilicifolia, nas concentrações testadas, inibiu o crescimento micelial do fungo $F$. oxysporum, estimulou o crescimento micelial de $C$. acutatum e apresentou frações que inibiram o desenvolvimento de Cylindrocladium spathulatum.

A grande importância da pesquisa assenta-se sobre o delineamento de novas propostas para o tratamento sanitário de plantas medicinais, uma vez que a legislação brasileira não apresenta produtos liberados para tal fim. Aliado tem-se propostas significativas, de alcance rápido e de baixo custo, para subsidiar a agricultura nacional.

\section{AGRADECIMENTOS}

Ao CNPq pelo suporte financeiro.

\section{REFERÊNCIAS BIBLIOGRÁFICAS}

ALONSO, J.R. Tratado de Fitomedicina: Bases Clínicas e Farmacológicas. Curitiba: Scientia et Labor, 1987.

AUER, C. G.; BETTIOL, W. Efeito da serapilheira de Eucalyptus grandis no crescimento micelial de Pisolithus tinctorius em meio de cultura. IPEF, n.32, p.49-51, 1986.

CARLINI, E.L.A. Estudos da ação antiúlcera gástrica de plantas brasileiras: Maytenus ilicifolia (Espinheira Santa) e outras. CEME/AFIP, p.5-20, 1988.

CORREA JUNIOR, C.; MING, L. C. \& SCHEFFER, M. C. Cultivo de Plantas Medicinais, Condimentares, Aromáticas. Jaboticabal: FUNEP, 1994.

KIMATI, H.; GIMENEZ-FERNANDES, N.; SOAVE, J.; KUROZAWA, C.; BRIGNANI NETO, F.; BETTIOL, W. Guia de fungicidas agrícolas - Recomendações por cultura. v.1. Jaboticabal: Grupo Paulista de Fitopatologia, 1997a.

KIMATI, H.; AMORIM, L. BERGAMIN FILHO, A . CAMARGO L.E.A, REZENDE, J.A.M. Manual de fitopatologia: doenças de plantas cultivadas. v.2. São Paulo: Editora Agronômica Ceres, 1997b.

LIMA, O. G. Substâncias antimicrobianas de plantas superiores - Sobre a presença de maitenina e pristimerina na parte cortical das raízes de Maytenus ilicifolia, procedente do Brasil Meridional. Revista do Instituto de Antibióticos, v.1, n.11, p.35-38, 1971.

STANGARLIN, J. R., SCHWAN-ESTRADA, K. R. F., SILVA CRUZ, M. E.; NOZAKI, M. H. Plantas Medicinais e Controle Alternativo de Fitopatógenos. Biotecnologia: Ciência \& Desenvolvimento, n.11, p.16-21, 1999.

STELLFELD, C. A espinheira-santa: contribuições ao estudo farmacognóstico. Boletim da Associação Brasileira de Pharmacia, ano XV, p.551-570,1934.

ZONTA, E. P.; MACHADO, A. A.; SILVEIRA JÚNIOR, P. Sistema de Análise Estatística para Microcomputadores (SANEST). Pelotas: UFPEL, 1984.

*Autor para correspondência:

Prof. Dr. Obdúlio G. Miguel

Laboratório de Fitoquímica - Depto. de Farmácia - Universidade Federal do Paraná.

Av. Prefeito Lothário Meissner, 3400, Jardim Botânico

80210-170 - Curitiba - PR

E-mail: obdulio@ufpr.br 